\title{
Significant others benefit from preoperative information
}

\author{
Edith Hunt Raleigh PhD RN \\ Research Fellow. The University of Michigan School of Nursing, Ann Arbor \\ Marybeth Lepczyk MSN RN CS \\ Gerontology Clinical Nurse Specialist, Harper Hospttal \\ and Constance Rowley MEd RN \\ Case Manager, Medical Product Line, Harper Hospital, Detrott, Michigan, USA
}

Accepted for publication 2 January 1990

RALEIGH E H, LEPCZYK M \& ROWLEY C (1990) Joumal of Advanced Nursing $15,941-945$

\section{Significant others benefit from preoperative information}

Little attention has been given to the preparation of the patient's family prior to surgery, even though nurses' clinucal expenence suggests that family members are often more anxious than the patient This study explored the knowledge and anxiety of spouses and significant others of patients preparing for cardiac surgery The subjects were selected by convenience from a preoperative class offered at the hospital where surgery was to occur Before and after the class, the subjects completed a cardiac-surgery knowledge test and an anxiety test The significant others were significantly more anxious than the patients pnor to the class. The anxiety level of significant others was significantly reduced after the class There were no statistically significant differences between patients and significant others on the cardiac-surgery knowledge test These results suggest that significant others may benefit from preoperative instruction

\section{INTRODUCTION}

Coronary artery bypass graft (CABG) surgery has become in recent years the chief means of treating symptomatic coronary artery disease While the surgery is farly commonplace to the health care workers who care for these patients, it is by no means commonplace for the patient or the patient's family Since the family is usually the major source of emotional support for the patient, an understanding of how they cope with the knowledge of pending surgery is relevant to helping the patient cope The purpose of this study was to determune the level of anxiety of the spouse or significant other compared to that of the patient about to undergo $C A B G$ surgery

\section{REVIEW OF THE LITERATURE AND CONCEPTUAL FRAMEWORK}

Preoperative instruction is accepted as beneficial for patients For instance, preoperative information about the surgical expenence has been found to reduce patient anxiety and aid in recovery (Lindeman \& VanAernam 1971, Schmitt \& Wooldndge 1973) One possible explanation for this phenomenon is found in stress and coping theory Lazarus \& Folkman (1984) theorized that humans cognitively appraise threatening situations to evaluate the balance of power between the harm-producing stumulus and their counterharm resources If the individual perceives that the counterharm resources (e.g knowing what to expect) are stronger than the stimulus (surgery), preoperative anxieties are reduced. Nurses may assist patients in strengthening resources through preoperative instruction 
The same phenomenon of cognitive appraisal is present in the family as well as the patient Preoperative instruction for the families of patients undergoing surgery has been largely ignored The nsks of surgery and a possible negative outcome pose a threat to the significant others Clinical expenence has suggested that family members often are more anxious than the patient pnor to surgery, perhaps because they expenence a sense of helplessness regarding the surgery According to Lazarus (1966), feelings of helplessness tip the balance of power toward the harmproducing stimulus (surgery, possible loss of loved one) Family members often feel there is little they can do but be present Even the patient maintains more control by being the one who has chosen to have the surgery The majonty of support is focused on the patient in the preoperative penod, thus, including the significant other in the preoperative teaching may validate their need for resources, including attention

Yet, few studies have examined the responses of the patient or family member when the family member receives preoperative instruction Those that have been done have suggested that involvement of families in the preoperative care of patients decreases both patient and family anxiety and increases patient co-operation and family satisfaction with care (Dziurbejko \& Larkin 1978, Visintainer \& Wolfer 1975)

A study by Leech (1982) explored the preoperative needs reported by patients awaiting reconstructive vascular surgery The convenience sample consisted of 60 patients, 40 men and 20 women Through interview, questionnare and hospital chart, 10 psychological, physiological and sociocultural needs were identified The two most frequently reported needs were for information and support The need for support was related to the amount of contact the patients had with their families The investigator concluded that the study strongly supported including the family in preoperative interventions whenever possible because of the impact they may have on the patient's well-being

\section{Interrelated behaviours}

There is some evidence that the behaviours and attitudes of patients and families are interrelated Laughlin (1967) described the contagion of emotions and defined this phenomenon as 'anxiety which anses by intuitive communication from one person to another' Based on this theory, Doerr \& Jones (1979) hypothesized that family members who received preparation regarding the coronary care unit would transmut less family-to-patient anxiety than would family members who did not receive this preparation The families of 12 coronary care patients were randomly assigned to information or no information groups The patient completed an anxiety questionnare before and after the family visited There were no significant differences in anxiety scores between the experimental and control groups on the pretest, yet the patients whose family members were prepared for the visitation showed a mean decrease of 167 points on the anxiety posttest which was significantly different from the control group Although the sample was small, these results support the importance of family involvement

In another study, Dziurbejko \& Larkın (1978) hypothesized that preoperative instruction that included the patient's family would produce even more beneficial effects than instructing the patient alone They randomly assigned 21 patients admitted for gynaecological surgery to one of three groups (1) patient-alone group, where only the patient received teaching, (2) patient-family groups, where both patient and family received teaching, and (3) control group, where the patient and family recerved no specific information The investigators reported that the patients in the patient-family group were more co-operative, expenenced less anxiety, asked fewer questions and made less postoperative demands Again, this study is limited by the small sample size

Silva (1979) explored the effects of preoperative information on spouses' anxieties and attitudes toward the patients' hospitalization and surgery Forty-eight spouses were randomly assigned to one of four experimental and control groups (1) onentation information, pretest and post-test, (2) no onentation information, pretest and posttest, (3) onentation information, post-test only, and (4) no onentation information, post-test only After the treatment, spouse anxiety and attitude were measured The spouses in the experimental groups had significantly more positive attitudes toward hospitalization and surgery and less anxiety on one of the two anxiety measures than did spouses in the control group Silva (1979) also reported that the majonty of pretested spouses were anxious and that they were more anxious than the presurgical patients

\section{Quality}

In another study, Silva (1987) found that 75 spouses of general surgical patients indicated their most important needs were 'related to reassurance about quality of patient care, avalability of the hospital staff and understandable information about the patient's hospitalization and surgery'

Gillis (1984) completed a longitudinal descriptive study of stress associated with coronary artery bypass surgery The study included two semistructured interviews and a 
questionnaire to gather data from 71 couples at the time of hospitalization and 6 months later Spouses had a significantly higher amount of stress Further analysis revealed that the difference seen in stress was not due to gender or family membership Apparently, greater stress is part of the role of being a patient's spouse Sources of stress reported by spouses were the wait for surgery, lack of control of hospital events, lack of privacy and lack of information about the hospital expenience and recovery

Another study (Stanley \& Frantz 1988) explored the social adjustment of spouses of patients who had undergone $C A B G$ surgery Twenty-six spouses were interviewed 4 to 10 weeks after their mate's bypass surgery Nineteen spouses reported a high level of vigilence (a need to watch over the patient) before and after surgery

To summarize, earlier studies have shown that spouses of patients identify a need for information about the patient's condition, hospitalization expenence and recovery Further, there is prelıminary evidence that involving the spouse in teaching programmes has a beneficial effect on the patient as well as spouse Also, there is some evidence that the spouse is more anxious about the hospital expenence than the patient

The major weakness in many of these studies, however, was the small sample sizes Using a larger sample, the purpose of this study was to examine whether the patient or significant other became more anxious as the surgical hour approached, and whether one or the other group was more knowledgeable In addition, it was hypothesized that the significant others would be more anxious than the patients pnor to cardiac surgery

\section{METHODS}

\section{Sample}

The convenience sample of volunteers was selected from a population of significant others who presented themselves with the patient at preoperative classes for cardiac bypass surgery at two large metropolitan hospitals Ninety per cent of potentral subjects agreed to participate Significant others were defined as any relative or friend who accompanied the patient to class $A$ total of 72 significant others and 74 patients were in the sample (Because other data were being collected which were specific to patients, the resulting patient sample was slightly larger ) The patients and significant others recerved the class pnor to admission at one hospital and after admission at the other hospital (usually the day before surgery)

\section{Instruments}

State-Tratt Anxiety Inventory (STAI)

This scale, developed by Spielberger et al (1970), consists of 20 short statements regarding present feelings in a Likert format Scores may range from 20 to 80 It has two forms based on the conceptualization of anxiety as having two dimensions State anxiety, a transitory emotional state, varies in intensity and over time Trait anxiety is considered to be a relatively stable characteristic which predisposes an individual to assess a vanety of situations as either benign or threatening The state anxiety form was used for this study Spielberger reported internal consistency coefficients (computed by formula K-R 20) ranging from 085 to 092 In this study, Cronbach's alpha coefficient for internal consistency was 090

\section{Heart Surgery Questionnatre}

This questionnaire, developed by the investigators, was used in three alternate forms for the pretest and post-tests It consisted of 14 multiple-choice questions related to the surgical experience in the following categories anatomy and physiology, procedures and policies, activity, and sensations to be expected Scores (the sum of correct responses) may range from 0 to 14 Content validity was established by a panel of three clinical nurse specialısts with expertise in cardiovascular nursing, using the class objectives There was $100 \%$ agreement among panel members Test-retest reliability in a pretest of the instrument using the first form with preoperative cardiac surgery patients $(n=20)$ yielded a correlation coefficient of 068 The test for internal consistency yielded a Cronbach's alpha of 076

\section{Background Questionnaire}

This questionnaire was developed by the investigators to gather socio-demographic data from the participants It included such things as mantal status, educational background and previous surgical expenences

\section{Procedure}

When significant others reported for preoperative class with the patients, their participation in the study was solicited, the study was explained and consent was obtained Pnor to class, the patient and significant other completed the Heart Surgery Questionnaure, the STAI and the Background Questionnaire The class took place I day to I week before the surgery After the class, they completed an alternate form of the Heart Surgery Questionnaire and STAI On the 
evening before surgery, they completed the third form of the Heart Surgery Questionnaire and STAI

\section{RESULTS}

The level of significance was set at 005 Of the 72 significant others, there were 62 females and 10 males which included 26 White and six Black participants The relationships of the particapants to the patients included 51 spouses, 11 adult children of the patient, and the other eight were spread as sibling, other relative or friend The significant others ranged in age from 18 to 73 with a mean of 4976 years $(\mathrm{SD}=1426)$

There were 59 male patients and 15 female The patients ranged in age from 32 to 75 with a mean age of 5914 years (SD =9.31) Sixty-five of the patients were marned Patients and significant others were excluded from the study based on the following patient critena (1) previous heart surgery, (2) other surgery in combination with the bypass surgery. (3) not fluent in written Enghish, and (4) emergency surgery There were no signuficant differences on demographic vanables between patients and significant others with the exception of age Patients were signifcantly older than significant others (paired $t=468$, d.f $=140, P<0001$ ) This was expected since significant others predominantly were wives and children Since there were no statistically significant differences between the preadmission and postadmission significant-other groups on knowledge or anxiety scores, they were treated, statistically, as one group for further analysis

\section{Anxiety}

In support of the hypothesis, significant others were significantly more anxious than the patients prior to the class (parred $t=399, \mathrm{df}=141, P<0001$ ) After the class, significant-other mean anxiety decreased (nonsignificantly) and was not significantly different from the patients' although it remained higher over all three tests Mean anxiety scores did not change significantly for significant others or patients as surgery approached In addition, there was no significant correlation between patient and signifcant other anxuety scores Figure 1 compares the means obtained on the STAI for patients and significant others

\section{Knowledge}

While not statistically significant (using paired $t$-test), the mean knowledge score among significant others was higher after teaching than before Before the class, the significant others scored a mean of $11.63(\mathrm{SD}=1.75)$ on the

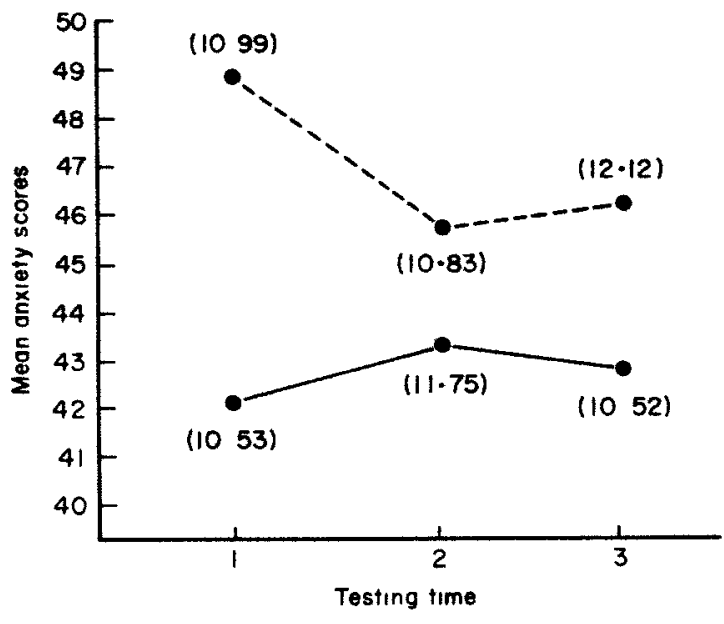

Figure 1 Comparison of patient and significant-other anxiety scores $-=$ patient, $---=$ significant other Standard deviations are in parentheses

Heart Surgery Questionnaire After class, they scored a mean of 1238 ( $(\mathrm{SD}=123)$ The patient means on these tests were $1133(\mathrm{SD}=247)$ and $1249(\mathrm{SD}=153)$ respectively The differences between the significant other and patient knowledge scores were not statistically significant

\section{DISCUSSION}

The results support the hypothesis that the significant others were more anxious than the patients pror to the class These findings support clinical observation and previous research (Laughlin 1967) Significant others may be more anxious because of a sense of helplessness, as theorized by Lazarus \& Folkman (1984), or the patient may be less anxious through a system of denial, or not thinking about the surgery, as a means of coping In addition, the patient may receive more social support than the significant other, thus providing more resources for coping

The lack of significant differences on anxiety after class is difficult to interpret Significant-other anxiety was expected to be significantly higher throughout the preoperative penod The significant-other results tend to support previous research with patients that suggest preoperative teaching will decrease anxiety (Lindeman \& VanAernam 1971, Schmitt \& Wooldndge 1973) Mean anxiety for significant others decreased slightly after class as mean knowledge increased sightly

Since the sample was defined by attendance at a preoperative class, the study was selective by including only those who chose to obtan information by structured means Thus, it was biased toward the information- 
seeker and did not consider the variable of preference for information One might assume that individuals who voluntanly attend a class are also those who prefer information While it may be argued that significant others may attend class to please the patient rather than to seek information, the knowledge scores show that the participants had obtained much of the tested information before attending class The additional information obtained was not enough to result in a significant increase in knowledge and may not have been enough to have a significant impact on anxiety scores

\section{Fear}

It may also be argued that fear rather than anxiety is the appropnate concept to be measured The concept of reflective fear encompasses a cognitive process as well as an emotional reaction According to Jones \& Jakob (1981), fear and anxiety should be differentrated Fear is defined as a reaction of apprehension to a specific danger while anxiety is defined as an uneasy sense of worry in reaction to an anticipated, nonspecific danger If the relevant experence preoperatively is fear, different information or a different type of intervention may be needed to effect a change in behaviour

\section{Significant others}

These findings do support the importance of including significant others in preoperative instruction While the significant other may benefit from it, they may also be enabled to be more supportive of the patient and transmit less anxiety It may also enable the significant other to be more supportive through reinforcing the information obtained

Significant others are an important support system for the patient Helping the significant other to cope with the surgical experience may result in positive outcomes for the patient Nurses may encourage significant others to attend by conducting class at a time convenient for the patient and significant others Further research should explore costeffective ways of imparting preoperative information to significant others and the patient Since they are coming to the hospital with information, it might be more cost effective to present the required information by mal prior to admission This would enable the patient and significant others to incorporate the information at their own pace and discuss it together. This and other methods need further exploration.

\section{Acknowledgements}

The authors would like to acknowledge the assistance of Lula Lester MSN RN, Mary Lee Van Keuren MSN RN, Kathleen West MSN RN and Kathleen Zimnick MSN RN for their assistance in data collection

This study was supported in part by a grant from the Amencan Heart Association of Michigan, Professional Nurses Research Grant Award The order of authorship was arbitrary

\section{References}

Doerr B \& Jones J (1979) Effect of family preparation on the state anxiety level of the CCU patient Nursing Research 28(5), 315-316

Dziurbejko M \& Larkın I (1978) Including the famıly in preoperative teaching Amencan Journal of Nursing 78, 1892-1894

Gillis C (1984) Reducing family stress durnng and after coronary artery bypass surgery Nursing Clinics of North Amenca 19(1), 103-112

Jones P \& Jakob D (1981) Nursing dragnosis Differentiatung fear and anxiety Nursing Papers/Perspectives In Nursing 4(13), 20-29

Laughlin H (1967) The Neuroses Butterworth, London

Lazarus R (1966) Psychological Stress and the Coping Process Mcgraw-Hill, New York.

Lazarus R \& Folkman S (1984) Stress, Appraisal, and Coping Springer, New York.

Leech J (1982) Psychosocial and physiologic needs of patients with arterial occlusive disease durng the preoperative phase of hospitalization Heart and Lung 11(5), 442-449

Lindeman C \& VanAernam B (1971) Nursing intervention with the presurgical patient - the effects of structured and unstructured preoperative teaching Nursing Research 20, 319-332

Schmitt F \& Wooldndge P (1973) Psychological preparation of surgical patients Nursing Research 22, 108-116

Silva M (1977) Spouses need nurses too The Canadian Nurse 73(12), 38-41

Silva M (1979) Effects of orientation information on spouses' anxieties and attitudes toward hospitalization and surgery Research in Nursing and Health 2, 127-136

Silva M (1987) Needs of spouses of surgical patients A conceptualization within the Roy adaptation model Scholarly Inquiry for Nursing Practice 1(1), 29-44

Spielberger C, Gorsuch R \& Lushene R. (1970) STAI Manual for the State-Trast Anxiety Inoentory Consulting Psychologists Press, Palo Alto, CA

Stanley M \& Frantz R (1988) Adjustment problems of spouses of patients undergoing coronary artery bypass graft surgery durng early convalescence Heart and Lung 17, 677-682

Visintainer M \& Wolfer J (1975) Psychological preparation for surgery pedatnc patients the effect on chuldren's and parents stress responses and adjustment Pediatrics 56, 187-202 
This document is a scanned copy of a printed document. No warranty is given about the accuracy of the copy. Users should refer to the original published version of the material. 